\title{
A note on name individuation and identifying descriptions
}

\section{JP Smit}

Department of Philosophy, Stellenbosch University, South Africa

E-mail: jps@sun.ac.za

\begin{abstract}
In "Public Proper names and Idiolectical Identifying Descriptions", Glezakos (2009) puts forward a theory concerning the role of identifying descriptions in the theory of names. Her main claim is that such identifying descriptions serve to individuate names, i.e. to make it the case that a given linguistic act containing a name $N$ contains $N$, and not some phonetically/orthographically equivalent name. In this paper, I will claim that, while a lot of what Glezakos has to say about the role of descriptions is probably correct, such descriptive conditions are not needed to solve the individuation problem.
\end{abstract}

Keywords: individuation, causal theory, reference

\section{A causal theory of the individuation of names}

Kripke's causal theory of reference states that the referent of a name $N$ is the individual that was baptised $N$ at the beginning of the causal chain of use from which the utterer of $N$ inherited $N$ (1980:91). Glezakos does not take issue with this type of view per se, but rather, following Kaplan (1990), points out that it stands in need of a standard for the individuation of names (2009:320). Her main claim is that descriptions do play some essential role in individuating the names that the causal theory is supposed to be about.

Consider, for instance, the case of the phonetic/orthographic type "Aristotle", which can be used to refer to either the famous philosopher or to the shipping magnate. Glezakos follows Kaplan (1990) in claiming that we have to - at least for the purposes of semantics and the theory of reference - treat these as distinct names. This raises the matter of individuation, i.e. the question as to what makes it the case that a given utterance is an utterance of one or the other name. Glezakos rejects the idea that we can give a causal criterion that answers this question successfully (2009:320). Rather, what happens is that speakers associate divergent descriptive conditions with the names and that these descriptive conditions guide their subsequent use of the two distinct names (2009:324). More importantly, these descriptive conditions serve to "keep the two names apart", i.e. they allow speakers to store and retrieve the two names that we write as "Aristotle" as two distinct names. This leads to an answer to the individuation problem: whether an utterance that contains the phonetic type "Aristotle" is an utterance of one or the other name depends on the descriptive conditions with which the name is associated. 
Note that, interestingly enough, it does not matter whether the descriptions are false, incomplete or otherwise deficient (Glezakos 2009:324). If a speaker, upon first hearing of the famous philosopher, associated "Aristotle" with "the great Roman biologist", then any subsequent utterance of "Aristotle" that is an attempt at uttering the name s/he associates with "the great Roman biologist" will count as an utterance of the philosopher's name. The descriptive conditions do not determine reference, but merely serve to keep track of a public name.

Glezakos presents her views after arguing that the standard conceptual apparatus used in the causal theory cannot serve to individuate names in a useful way (2009:320-322). I will argue that her arguments are flawed and that the conceptual apparatus used in the causal theory can, in fact, serve to individuate names. I will proceed by stating a specific version of the causal theory of the individuation of names before showing that her arguments do not undermine it.

Kripke (1980), in "Naming and Necessity", did not say much about the individuation of names. He did, however, suggest that phonetically identical sounds should count as distinct names if they name distinct objects (1980:8). This suggests individuation by reference which, for reasons briefly explained below, I will not adopt. He also, however, in a footnote to this remark, suggests a slightly different option:

$[\mathrm{O}] \mathrm{n}$ the picture advocated in this monograph, two totally distinct 'historical chains' that by sheer accident assign phonetically the same name to the same man should probably count as distinct names despite the identity of referents.

(1981:8n)

Kripke states that he does not advocate ${ }^{1}$ or reject this standard of individuation (1981:8n). I will, however, take the idea seriously and use it as a standard against which Glezakos' arguments can be tested. Call it the "Baptismal Standard". This standard, of course, is not the only one that would be consistent with his remark, but is both consistent with what he said and plausible for independent reasons.

Baptismal Standard: Tokens of a name $N$ are tokens of the same type in virtue of being causally related to the same baptismal event.

In his causal theory of reference, Kripke states that the causal chain in question must be "of the required type" (1981:96n). A causal chain is only of the required type if each speaker in such a chain intends to use the name to refer to the same individual that the previous speaker in the chain referred to (1981:96). This has the virtue of "breaking the chain" when an existent phonetic type is used to baptise someone anew, and avoids the absurdity of claiming that all phonetic types refer to the unique individual that was originally baptised using that phonetic type. The reference to causal relations in the Baptismal Standard should be read in the same way and for the same reason.

Note that an acceptance of the Baptismal Standard of individuation does not force one to adopt a causal theory of reference. It is, as pointed out by Almog (1984:481-484), even compatible with descriptivism about reference determination. Also note that the Baptismal Standard does not mean that a name, individuated in terms of a given baptism, will always refer to the baptised

\footnotetext{
${ }^{1}$ However, Kaplan does advocate such a standard in Kaplan (1990).
} 
individual. Rather, the matter as to whether a name can change its reference is left open. This is important as it means that Evans' famous case of "Madagascar", which used to refer to one geographic entity and later referred to another (Evans 1982), counts only against the causal theory of reference, and not the Baptismal Standard of individuation. In fact, the Baptismal Standard of individuation provides a natural way of making sense of the claim that a single name used to refer to one object and then came to refer to another ${ }^{2}$.

\title{
2. The Baptismal Standard and Glezakos' view
}

Glezakos (2009:320) considers a case where she acquires the name "Aristotle" (the philosopher) from Mary. Later on she acquires a distinct "Aristotle" from Jane. She then utters "Aristotle was a pretty good philosopher". This raises the question as to which of the two names she used and why. Glezakos argues as follows:

\begin{abstract}
Maintaining that there is a 'causal' or 'historical' connection between my utterance and the first of those past conversations will not suffice to account for my having retrieved one name rather than the other. After all, neither of the earlier conversations 'caused' me to produce my utterance today. Rather, I recalled that some time earlier I had heard about a Greek who wrote about biology and logic and ethics, felt pretty confident that the Greek's name was 'Aristotle', and spoke up [...] My use forged a new link in a causal chain tracing through Jane all the way back to the name's introduction, and that is why I referred to the object that I did. The causal chain cannot, however, provide the explanation for why my utterance contained the particular public name that it did.
\end{abstract}

$(2009: 320-321)$

It is hard to know what to make of the above passage. The Baptismal Standard gives the correct result in such a situation, and does so in a quite straightforward way. The use of "Aristotle" is causally related to the original conversation with Mary, which is causally related to the original baptism of Aristotle, and hence this use of "Aristotle" should, on the Baptismal theory, count as being a use of the name of the philosopher. This would seem to be plain on, for instance, a counterfactual construal of causality. If the original baptism of Aristotle had not taken place, then the conversation with Mary would not have included the name "Aristotle", and the subsequent "Aristotle"-involving utterance would not have happened. This holds on any respectable construal of causality; the basic fact is that the original baptism of the philosopher forms part of the explanation of the subsequent utterance in a way that a baptism of, for instance, Onassis, simply does not. Glezakos, in the above piece, claims that neither of her earlier conversations caused her to produce the utterance (2009:320), but this seems plainly false. It is, of course, true that neither of the conversations was a sufficient cause of her utterance, i.e. that neither conversation compelled her to make the utterance, but this is irrelevant as all that is needed is that there is some sort of causal chain at play that originated in an original baptism. The same goes for her claim that the causal chain cannot explain her utterance (2009:320). It is true that the causal chain does not fully explain why she made the utterance, but this is irrelevant. The original baptism does play some small but essential explanatory role, and that is all that it needs to do.

\footnotetext{
${ }^{2}$ Individuation in terms of the baptised individual would also not be able to handle cases where no individual was, in fact, baptised.
} 
Given that the Baptismal Standard gives the correct answer, as is obvious on a counterfactual construal of causality, it is puzzling why Glezakos makes the claims that she does. I suspect that there are two major confusions that underlie such a view, and will discuss them in turn.

\section{Names in the mental "black box"}

The first confusion is the confusion between the individuation of words and the way in which people keep track of what a word refers to. Glezakos states that people associate names with descriptive conditions and that such conditions guide their subsequent use of a name and serve to idiolectically individuate words. These claims may well be correct. Whether a public name refers to one person or another is a socially established, empirical fact - it is something that an individual person can get right or wrong. This means that, in order to be able to employ a name with any sort of warrant, a person has to have semantic beliefs about what public names refer to. It is at least plausible to argue that such beliefs must be cast largely in terms of descriptive conditions that the person believes that the referent of the name fulfils. Such semantic beliefs will then serve to guide the speaker in employing the name. This would mean that descriptive conditions do play some essential role in the theory of communication and language use. Hence, I think that Glezakos is correct in her construal of the cognitive and communicative roles played by descriptions. It does not, however, follow from this that such descriptions play any role in individuating public names. We can still individuate an uttered name in terms of the causal chain that gave rise to the utterance.

The second and more basic confusion concerns the matter of the cognitive storage and retrieval of names. Glezakos claims that the descriptive conditions not only allow a speaker to usefully employ a name, but also serves as a standard of individuation for the name. In doing so, she echoes concerns regarding the "intrapersonal continuity" of causal chains that were originally expressed by Kaplan (1990). The problem, as put by Kaplan, is that we do not know what to make of the notion of the continuity of a name when the name is in the cognitive "black box" that mediates between the acquisition of a name and its subsequent use (1990:102).

I think that this problem is overblown. There are two possibilities as to how this could happen in any information-processing mechanism. The first possibility is that the two names remain distinct, i.e. that they are stored in different "locations". If this is the case, then it always makes sense, with regard to a stored name, to speak of the causal chain that gave rise to it being stored, and such a chain will always originate in a baptism. It will also always make sense to ask whether a stored name would have existed if a certain baptismal ceremony had not taken place. It is, of course, the case that these facts about causal chains will be of no help in guiding the behaviour of a language speaker in making judgments that use the name. Here I am fully in agreement with Glezakos' claim that descriptive conditions will play a large role in guiding linguistic behaviour and in helping the language user to keep track of which name is which. But this merely makes such descriptions an epistemic device employed by the speaker to track a fact that depends on the relevant causal chains; it does not serve to make the causal chains individuating criteria. To give an analogy, consider a case where I receive two indistinguishable physical objects at a distinct time. Suppose that the object received first has great sentimental value, and so I wish to keep track of which object is which. I now put different colour Post-It ${ }^{\mathrm{TM}}$ notes on the two objects in order to track which object I received first. In such a case, the Post-It ${ }^{\mathrm{TM}}$ notes do not serve to individuate the two objects; rather they are an epistemic device that allows me to keep track of 
which object is which. The objects are still individuated by whatever causal-structural properties physical objects are normally individuated by.

The second possibility concerning how the mind keeps track of semantic beliefs would be one in which the names are not stored as distinct entities. Let us assume that the mind stores all semantic beliefs concerning names as a kind of list. This list is ordered by phonetic and/or orthographic type, much as a dictionary is ordered. Next to each phonetic/orthographic type is a list of the people who can be referred to by using that phonetic/orthographic type, and these are identified by descriptive conditions. Hence, next to a generic name like "David", there would be several entries, each listing various facts about the various individuals that we refer to as "David".

The above seems to represent a kind of worst-case scenario. Not only are the distinct names not being kept distinct, but no effort is being made to do so. This, however, would still not be any problem for a Baptismal Standard of individuation. What happens in such a case is that it no longer makes any sense to ask, with regard to the stored phonetic/orthographic type, which of the distinct names it is. Rather, all we have is a stored phonetic/orthographic type, and information enabling the speaker to appropriately use the different names stored in this way. And yet the subsequent utterance of a name can still be causally connected to an original baptism, i.e. we can link such an utterance to the baptismal event that helps to explain the eventual utterance. Telling a causal story about the use of a name, where one link in the causal chain that produced the use of the name is a list containing the generic name and the specific descriptive conditions associated with it, poses no intrinsic difficulties.

The only odd feature of the above situation is that, at one point in the causal chain, it makes no sense to ask which specific name (i.e. one name as opposed to a phonetic/orthographic equivalent) is stored at a certain location. Rather, one link in the causal chain only includes information about a phonetic/orthographic type and its proper use. An analogy can serve to make this seem less strange. Suppose I win a million dollars in a lottery and deposit it into my bank account. (Note that most currency does not exist in the forms of notes and coins; most currency merely exists in the form of account entries in the ledgers of institutions like banks.) If I keep my lottery money in a separate account from the one I normally use, then I can meaningfully point at the former and say that it is my lottery money, and point at the latter and say it is not my lottery money. This case is a bit like the one mentioned first, the one where I store two names in different "locations" in my mind. In such a case, it is meaningful to ask, with regard to one piece of stored information, which name is being stored.

Consider a case, however, where I deposit my lottery money into the same account in which I keep the rest of my money. Stipulate that I now have two million dollars in the account, and remember that there are no physical notes and coins underlying such a transaction. It now makes no sense to ask, with regard to the two million dollars, which is lottery money and which is not. The only fact of the matter is that the bank recognises that I have two million dollars; there are no individual dollars that can be separately tracked. Yet, if I now spend a million dollars on a house, we can still make sense of the claim that I spent my lottery money on the house. If there is a causal link between winning the lottery and buying the house, i.e. if, at a bare minimum, I would not have bought the house if I had not won the lottery, then no one is going to, based on arcane issues concerning currency individuation, object to my claim that I bought the house with the lottery money. 
The above case is like the scenario where I store two separate names (say, two instances of the generic name "David") under one phonetic/orthographic type. In such a case, it makes no sense to ask which of the phonetically or orthographically identical occurrences of "David" is stored in a specific place; the distinction no longer applies. Yet, if I subsequently use the name "David", and such a use is causally dependent on a specific baptismal event, it again makes sense to say that I used one "David" and not the other.

The above reasoning shows that there is no special problem of intrapersonal name continuity for definite descriptions to resolve. It does not matter how names are stored in the mental "black box", we can always apply a causal criterion of name individuation to utterances of logically distinct yet phonetically/orthographically identical names. No doubt, descriptive criteria play an essential epistemic role in guiding our usage of names. This, however, is not a good reason to suppose that they also have an individuating role.

\section{References}

Almog, J. 1984. Semantical anthropology. In P. French, T. Vehling and H. Wettstein (eds.) Midwest studies in philosophy IX. Minneapolis: University of Minnesota Press. pp. 479-489.

Evans, G. 1982. In J. MacDowell (ed.) The varieties of reference. New York: Oxford University Press.

Glezakos, S. 2009. Public proper names and idiolectical identifying descriptions. Linguistics and Philosophy 32: 317-326.

Kaplan, D. 1990. Words. Proceedings of the Aristotelian Society, Supplementary Volume LXIV. pp. 93-119.

Kripke, S. 1980. Naming and necessity. Cambridge: Harvard University Press. 